\title{
KNOWLEDGE, ATTITUDES AND PREFERENCES AMONG SPANISH COMMUNITY PHARMACISTS REGARDING INHALED THERAPY (THE OPTIM PHARMACY STUDY)
}

\author{
JORDI GINER ${ }^{1}$, PERE ROURA², BERTA TORRES ${ }^{3}$, FELIP BURGOS ${ }^{4}$, DIEGO CASTILLOํㅜ, EDUARD TARRAGONA ${ }^{5}$, \\ VICENTE PLAZA ${ }^{1}$
}

1Department of Respiratory Medicine, Hospital de la Santa Creu i Sant Pau, Institut d'Investigació Biomédica Sant Pau (IIB Sant Pau), Universitat Autònoma de Barcelona, Barcelona, Spain, ${ }^{2}$ Department of Clinical Epidemiology and Research, Hospital General de Vic, Vic, Barcelona, Spain, ${ }^{3}$ Pharmacist, Barcelona, Spain, ${ }^{4}$ Respiratory Diagnostic Center, Department of Respiratory Medicine (ICR), Hospital Clínic de Barcelona, Institut d'Investigacions Biomèdiques August Pi i Sunyer (IDIBAPS). Universitat de Barcelona, Barcelona; and Center for Biomedical Metwork Research in Respiratory Diseases (CIBERES), Spain, ${ }^{5}$ Medical Department, Chiesi España, S. A., L'Hospitalet de Llobregat, Barcelona, Spain

Email: jginer@santpau.cat

Received: 29 Mar 2016 Revised and Accepted: 22 Jul 2016

\section{ABSTRACT}

Objective: To assess knowledge, attitudes, and preferences regarding inhaled therapy among Spanish community pharmacists.

Methods: An 11-item questionnaire was developed and distributed to community pharmacists throughout the country. Data collected included demographics, the source of knowledge of inhaler use, known and preferred devices, steps for correct use of metered-dose (pMDI) and dry-powder (DPI) inhalers, important variables when prescribing an inhaler device, patient education, and checking inhaler technique.

Results: Of a total of 3000 questionnaires delivered, 1722 (57.4\%) were returned. The most common source of knowledge was the package insert (46.9\%) followed by personal experience (33.3\%). Diskus ${ }^{\mathrm{TM}}$ and Turbuhaler ${ }^{\mathrm{TM}}$ were the best-known devices ( $96.4 \%$ and $93.4 \%$ ), and DPIs the preferred inhalers. Although more than half of the surveyed pharmacists were aware of the most important step for correct inhalation with pMDI and DPI, only $18 \%$ identified the correct answer 'Patient's preference' as the most important variable when prescribing an inhaler device. Most of the respondents had inadequate knowledge of inhaled therapies. Statistically, significant differences were found according to geographical areas. Moreover, the mean score on inhaled therapy with one knowledge source was higher than for those with none $(\mathrm{P}<0.05)$. Additionally, patient education was poor.

Conclusion: In spite of the increasing involvement of Spanish community pharmacists in patients' care, their knowledge of inhaler use and attitudes towards inhaled therapy needs to improve, so that they can provide better patient education.

Keywords: Inhaler devices, Inhalation techniques, Community pharmacist, Misuse of inhalers

(c) 2016 The Authors. Published by Innovare Academic Sciences Pvt Ltd. This is an open access article under the CC BY license (http://creativecommons. org/licenses/by/4. 0/) DOI: http://dx.doi.org/10.22159/ijpps.2016v8i9.11796

\section{INTRODUCTION}

Drug delivery by inhalation allows faster onset of action and causes fewer and milder adverse events as compared with systemic delivery routes [1]. Although inhaled therapy can be utilized in a variety of diseases [2], its main use is in obstructive respiratory diseases. Inhaled therapy is the recommended treatment of choice in the clinical guidelines for asthma [3, 4] and chronic obstructive pulmonary disease (COPD) $[5,6]$. Many inhalation devices are currently available, thus allowing customized prescriptions. However, this wide range of devices also represents a drawback because healthcare providers should know the different types and the differences between them.

Moreover, benefits of inhaled therapy can be limited by inadequate inhalation maneuvering and inhaler handling $[7,8]$. The main problem with inhalers is the inhalation technique especially with pressurized metered-dose inhalers (pMDIs) [4]. Even though the newest drypowder inhalers (DPIs) can be easier to use than older devices [9], patient education is paramount. For that reason, the main guidelines on asthma and COPD, such as GINA (Global Initiative for Asthma) [3], GEMA (Spanish Guide for Asthma Management) [4], and GOLD (Global Initiative for Chronic Obstructive Lung Disease) [6] recommend patient education and training in all stages of the disease. Training and follow-up in the use of inhalation devices are regarded as the most important steps in education programs. Similarly, national societies such as the Spanish Society of Pneumology and Thoracic Surgery (SEPAR) [10] and international societies such as the European Respiratory Society (ERS) and the International Society of Aerosol in Medicine (ISAM) [11] have developed guidelines and consensus reports for the use of inhaled therapy.
Community pharmacists have an important role in education and training of patients with obstructive respiratory diseases $[3,12]$. As shown in a COPD case finding a program in community pharmacists as a new strategy to reduce COPD underdiagnosis [13], community pharmacists were able to select and assessed patients using a questionnaire and spirometric testing. Also, when pharmacists have been trained, results of their intervention in educational programs were similar to those obtained by physicians and/or nurses $[3,4]$. Pharmacists working in community pharmacies should be included in interdisciplinary teams to educate patients and thus obtain the maximum benefit from inhaled therapy [14-18].

The OPTIM Pharmacy Study is a project aimed to assess knowledge, attitudes, and preferences regarding inhaled therapy among health care providers in Spain. In two previous national surveys regarding the level of knowledge and attitudes of both practicing physicians from specialties that frequently prescribe inhaler devices [19] and nurses working with respiratory patients using inhaler devices [20], knowledge of inhalers and inhalation techniques remains poor in Spain. The present study was designed to assess knowledge about inhalation therapy in the third group of professionals involved in respiratory patients' care: pharmacists, specifically those working in community pharmacies.

\section{MATERIALS AND METHODS}

\section{Design and study population}

This was a cross-sectional survey study, the objective of which was to assess the level of knowledge, attitudes, and preferences related to inhaled therapy among community pharmacists. Between May and November 2014, a questionnaire specifically designed for the study 
was distributed to community pharmacists throughout Spain by sales representatives of a pharmaceutical company (Chiesi España).

\section{Questionnaire}

An 11-item questionnaire (table 1) was developed based on those used in the prior surveys among Spanish physicians [19] and nurses [20]. Moreover, responses to items 6 to 8 were scored as 0 (incorrect response) or 1 (correct response).

The sum of the scores allowed respondents to be classified according to their general knowledge of inhaled therapy: null or no knowledge ( 0 points), poor ( 1 point), limited ( 2 points), and adequate ( 3 points).

Table 1: Administered questionnaire

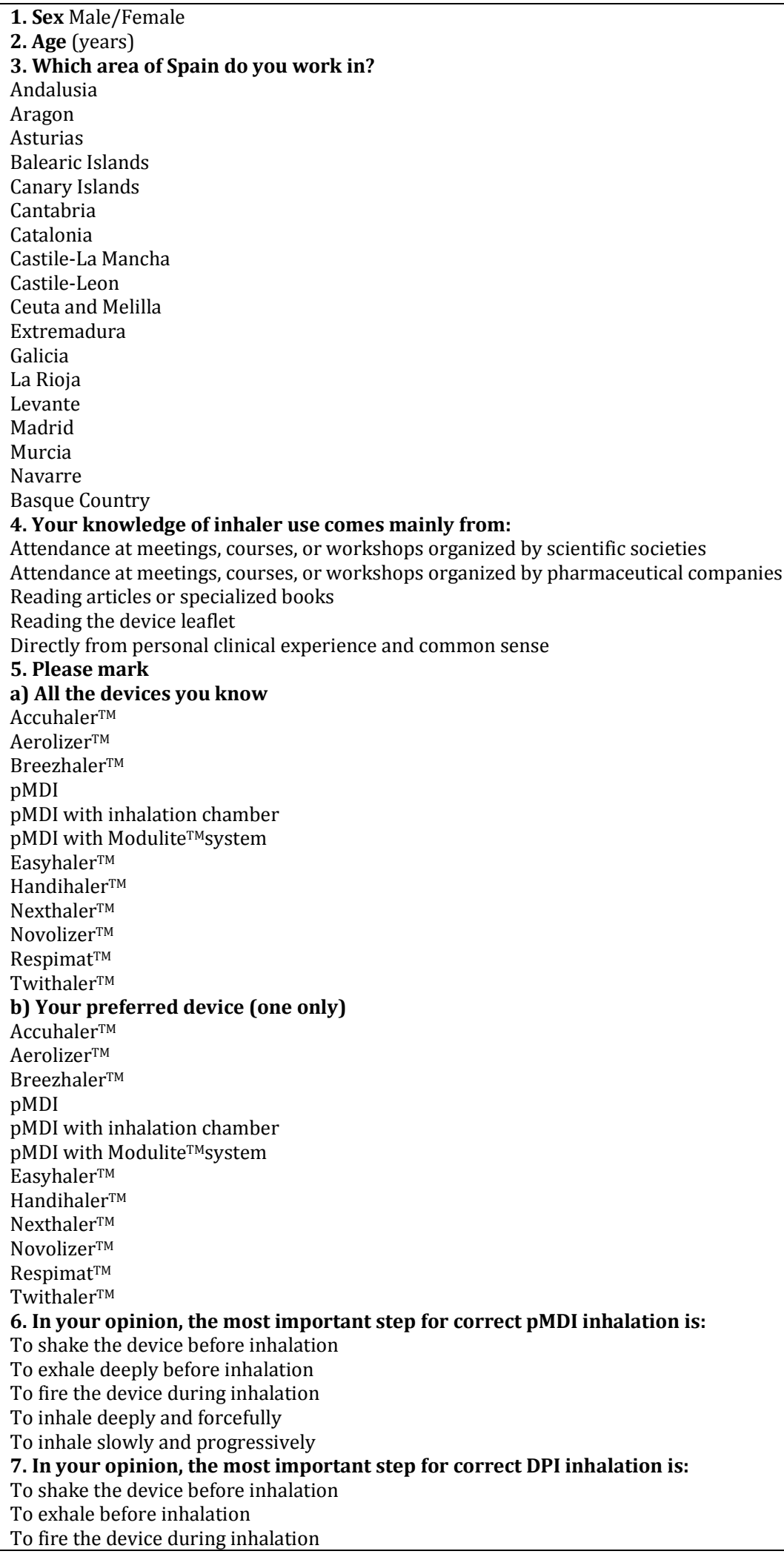




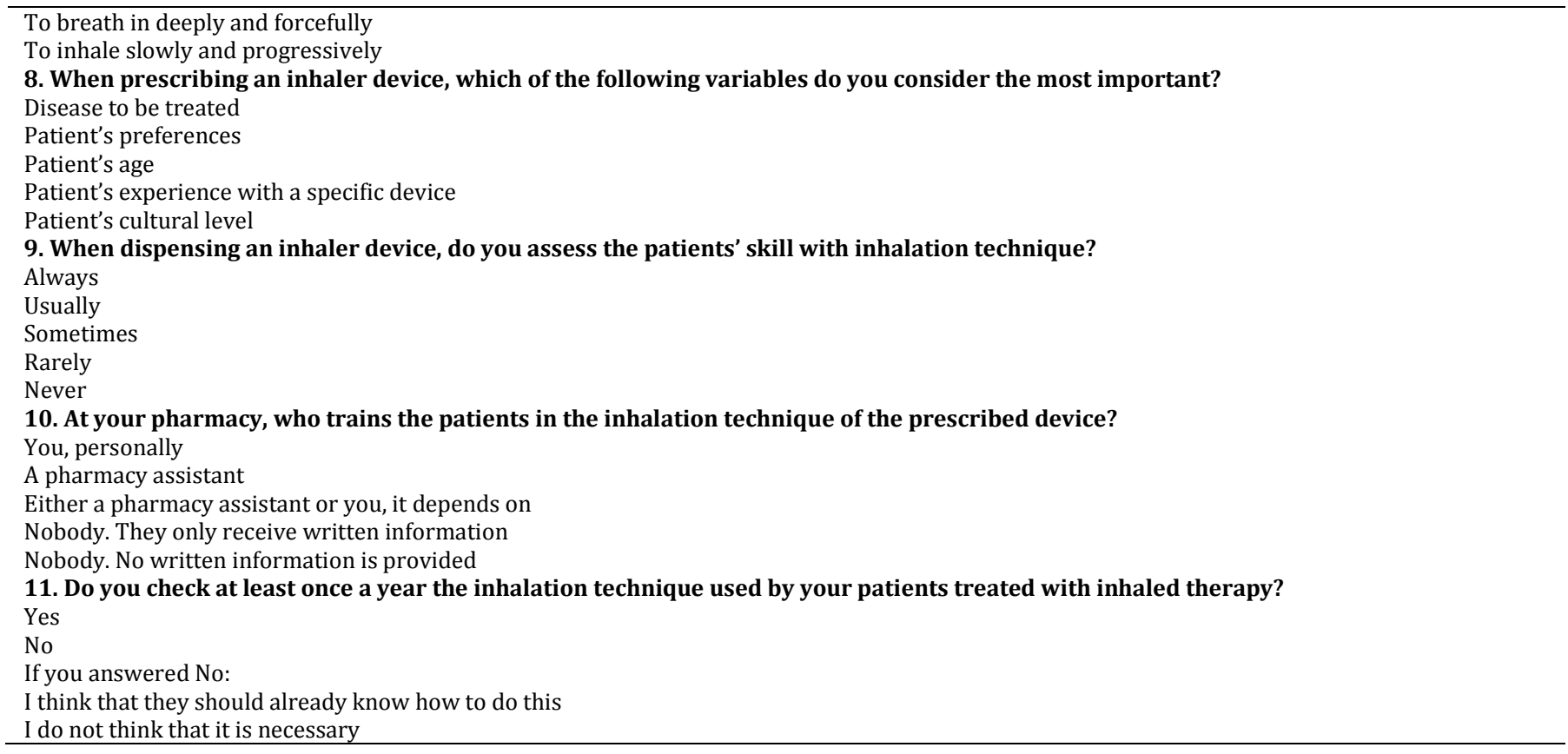

DPI, dry-powder inhaler; pMDI, metered-dose inhaler, aPercentages were estimated based on the number of valid answers.

\section{Statistical analysis}

Categorical variables were expressed as frequencies and percentages, and continuous variables as mean and 95\% confidence interval (CI). When the questionnaires were not fully completed, the response rates for each incomplete item were calculated on valid responses. Descriptive statistics were gathered and the results were expressed as a number of respondents, percentages, and valid percentages. Additionally, scores were analyzed using contingency tables, chi-square test and analysis of variance (ANOVA) to assess general knowledge of inhaled therapy. Statistical significance was set at a $\mathrm{P}$ value $<0.05$. Analyses were performed using Statistical Package for the Social Sciences (SPSS Inc., Chicago, IL, USA) version 19 for Windows.

\section{RESULTS}

Of a total of 3000 questionnaires delivered during the survey period, 1722 (57.4\%) were returned.

\section{Demographic characteristics}

There were 747 men and 949 women (missing data, $n=26$ ), with a mean age of 46.6 y (95\% CI 45.7 to 47.5 ) (range 20-81 y) (missing data for age, $n=53$ ).

Most pharmacies were located in towns with a population of over 5000: 1389 pharmacies vs. 298 in towns with a lower population.
This question was not answered in 35 questionnaires. Thus, the valid percentages were $82.3 \%$ and $17.7 \%$, respectively.

As far as the Spanish geographical area where pharmacists were working, and excluding the 13 questionnaires with missing data, numbers and valid percentages were as follows: $318(18.6 \%)$ in the Northern area, $410(24.0 \%)$ in the Central area, $343(20.1 \%)$ in the Southern area, 609 (35.6\%) in the Eastern area, and $29(1.7 \%)$ in the Canary Islands, Ceuta and Melilla. This geographical allocation is a grouping of autonomous communities and cities corresponding to the commercial areas of Chiesi España.

\section{Knowledge sources}

The most important source of knowledge was the package insert of the devices, followed by the pharmacist's personal experience (table 2). The answer and percentage totals in table 2 are higher than 1722 and $100 \%$, respectively, because respondents were able to choose more than one answer. By a number of knowledge sources, 56 respondents (3.3\%) declared no source, 1309 (76.0\%) only one source and 357 (20.7\%) more than one. This last group included two sources reported by 240 respondents (13.9\%), three sources reported by 92 respondents (5.3), four sources reported by 17 respondents (1.0\%), and five sources reported by 8 respondents $(0.5 \%)$.

Table 2: Knowledge sources

\begin{tabular}{ll}
\hline Item & No. (\%) \\
\hline 4. Your knowledge of inhaler use comes mainly from: & $196(11.4)$ \\
Attendance at meetings, courses, or workshops organized by scientific societies & $328(19.0)$ \\
Attendance at meetings, courses, or workshops organized by pharmaceutical companies & $268(15.6)$ \\
Reading articles or specialized books & $808(46.9)$ \\
Reading the package insert & $573(33.3)$ \\
Directly from personal clinical experience and common sense &
\end{tabular}

\section{Known and preferred inhalers}

Among inhalation devices available in Spain, Diskus ${ }^{\mathrm{TM}}$ (Accuhaler $^{\mathrm{TM}}$ in Spain) was the best known, followed by Turbuhaler ${ }^{\mathrm{TM}}$, while Twisthaler ${ }^{\mathrm{TM}}$ was the least known (table 3). The sums of answers and percentages in table 2 are higher than 1722 and $100 \%$, respectively, because item 5 a also allowed multiple responses. This question was not answered by 22 respondents.
By number of inhalers known, 245 respondents (14.2\%) were familiar with the 13 proposed devices. When the numbers of known inhalers were grouped, 22 respondents $(1.3 \%)$ did not mark any device; 634 (36.8\%) knew from 1 to $6 ; 549$ (31.9\%) from 7 to 9; and $517(30 \%)$ knew ten or more inhalers. Nexthaler ${ }^{\mathrm{TM}}$ was the preferred inhaler, followed by Accuhaler ${ }^{\mathrm{TM}}$, while Twisthaler ${ }^{\mathrm{TM}}$ was the least preferred (table 4). 
Table 3: Knowledge of inhalers

\begin{tabular}{|c|c|}
\hline Item & No. (\%) \\
\hline \multicolumn{2}{|l|}{ 5a. Which device do you know? } \\
\hline Accuhaler ${ }^{\mathrm{TM}}$ & $1660(96.4)$ \\
\hline AerolizerTM & $804(46.7)$ \\
\hline Breezhaler ${ }^{\mathrm{TM}}$ & $956(55.5)$ \\
\hline pMDI & $1297(75.3)$ \\
\hline pMDI with inhalation chamber & $1116(64.8)$ \\
\hline pMDI with Modulite ${ }^{\mathrm{TM}}$ system & $894(51.9)$ \\
\hline Easyhaler ${ }^{\mathrm{TM}}$ & $703(40.8)$ \\
\hline HandihalerTM & $828(48.1)$ \\
\hline Nexthaler ${ }^{\mathrm{TM}}$ & 1304 (75.7) \\
\hline Novolizer ${ }^{\mathrm{TM}}$ & $664(38.6)$ \\
\hline Respimat $^{\mathrm{TM}}$ & $1008(58.5)$ \\
\hline Turbuhaler ${ }^{\mathrm{TM}}$ & $1608(93.4)$ \\
\hline Twisthaler ${ }^{\mathrm{TM}}$ & $562(32.6)$ \\
\hline
\end{tabular}

pMDI, pressurized metered-dose inhaler

Table 4: Preference for one inhaler

\begin{tabular}{ll}
\hline Item & No. (\%) \\
\hline 5b. Which device do you prefer? & $368(25.7)$ \\
Accuhaler & $22(1.5)$ \\
Aerolizer & $26(1.8)$ \\
Breezhaler & $75(5.2)$ \\
pMDI & $125(8.7)$ \\
pMDI with inhalation chamber & $46(3.2)$ \\
pMDI with Modulite ${ }^{\mathrm{TM}}$ system & $15(1.0)$ \\
Easyhaler & \\
Handihaler $^{\mathrm{TM}}$ & $27(1.9)$ \\
Nexthaler $^{\mathrm{TM}}$ & $385(26.9)$ \\
Novolizer & $9(0.6)$ \\
Respimat $^{\mathrm{TM}}$ & $55(3.8)$ \\
Turbuhaler & $274(19.1)$ \\
Twisthaler & $6(0.6)$ \\
\hline
\end{tabular}

pMDI, pressurized metered-dose inhaler

By type of preferred device, 1132 respondents $(79.0 \%)$ answered DPIs, 246 (17.2\%) pMDIs and 55 (3.8\%) Respimat ${ }^{\mathrm{TM}}$. A further 289 respondents (16.8\% of questionnaires returned) did not answer the question or marked more than one preferred device.

\section{Knowledge of inhalation techniques and prescription}

More than half of the respondents answered correctly that the most important step for a correct inhalation technique using pMDI devices is firing the device during inhalation (table 5). In contrast, 77 respondents did not answer this question or marked more than one option.

Similarly, more than half of the respondents stated correctly that the most important step for correct PDI inhalation is to breathe in deeply and forcefully (table 4). Fifty-three respondents did not answer this question or marked more than one option.

Table 5: Knowledge of inhalation techniques and prescription

\begin{tabular}{ll}
\hline Item & No. (\%) \\
\hline 6. The most important step for correct pMDI inhalation is: & $152(9.2)$ \\
To shake the device before inhalation & $195(11.9)$ \\
To exhale deeply before inhalation & $912(55.4)$ \\
To fire the device during inhalation & $174(10.6)$ \\
To inhale deeply and forcefully & $212(12.9)$ \\
To inhale slowly and progressively & $37(2.2)$ \\
7. The most important step for correct DPI inhalation is: & $259(15.5)$ \\
To shake the device before inhalation & $179(10.7)$ \\
To exhale deeply before inhalation & $929(55.7)$ \\
To fire the device during inhalation & $265(15.9)$ \\
To inhale deeply and forcefullya & \\
To inhale slowly and progressively & $438(26.6)$ \\
8. When prescribing an inhaler device, which of the following variables do you consider the most important? & $304(18.5)$ \\
Disease to be treated & $335(20.3)$ \\
Patient's preferences & $478(29.0)$ \\
Patient's age & $92(5.6)$ \\
Patient's experience with a specific device & \\
Patient's cultural level & \\
\hline
\end{tabular}

DPI, dry-powder inhaler; pMDI, pressurized metered-dose inhaler. aCorrect answer. 
Regarding the most important variable when prescribing an inhaler, the most frequent answer was "Patient's experience with specific devices" (table 4), but this answer was incorrect. Roughly $18.5 \%$ of pharmacists surveyed answered correctly "Patient's preferences". As in previous items, some respondents $(n=75)$ did not answer or marked more than one option.

\section{Patient education}

Most of the respondents reported that, when dispensing the inhaler, they only sometimes or rarely assessed the patient's skills with the device (table 6). Ten respondents $(0.6 \%)$ did not answer this question.

Table 6: Patient education

\begin{tabular}{lc}
\hline Item & No. (\%) \\
\hline 9. When dispensing the device, do you assess the patient skill with its use? & $133(7.8)$ \\
Always & $313(18.3)$ \\
Usually & $673(39.3)$ \\
Sometimes & $450(26.3)$ \\
Rarely & $143(8.4)$ \\
Never & $208(12.2)$ \\
10. At your pharmacy, who trains the patients in the inhalation technique? \\
A pharmacist & $122(7.2)$ \\
A pharmacy assistant & $812(47.6)$ \\
Either a pharmacist or a pharmacy assistant & $564(33.1)$ \\
Nobody. We asked them if they have been trained & $459(26.7)$ \\
11. At your pharmacy, do you check the inhalation technique of your customers? & $1263(73.3)$ \\
Yes & \\
No & \\
If you do not, why not? & $857(71.7)$ \\
I do not think that it is necessary & $338(28.3)$ \\
\hline
\end{tabular}

With regard to the training of patients in inhalation technique, the most frequent answer was "Either a pharmacist or a pharmacy assistant". However, one-third of respondents stated that they do not train them and that they ask the patients if they have been educated by their doctor or nurse (table 6). Sixteen respondents $(0.9 \%)$ did not answer.

Finally, only about a quarter of the respondents checked the inhalation technique of their patients. Among those who did not check the inhalation technique, most respondents considered that the patients should already be familiar with it (table 6) and 68 respondents $(5.4 \%$ of those who did not check the inhalation technique) did not answer.

\section{Analysis of inhaled therapy knowledge}

Most of the respondents had an inadequate or limited knowledge of inhaled therapy, while only a small percentage had an adequate knowledge (table 7).

Table 7: Score distribution of inhaled therapy knowledge

\begin{tabular}{lll}
\hline Knowledge level & Frequency & \% \\
\hline Null or no knowledge (0 points) & 301 & 17.5 \\
Inadequate (1 point) & 667 & 38.7 \\
Limited (2 points) & 650 & 37.7 \\
Adequate (3 points) & 104 & 6.0 \\
\hline
\end{tabular}

Results showed no statistically significant differences according to sex (chi-square test, $\mathrm{P}=0.96$ ), age of respondents (Kruskall Wallis test, $\mathrm{P}=0.30$ ), and population size of the town where their pharmacy office was located (data not shown) (chi-square test, $\mathrm{P}=0.29$ ). However, differences among geographical areas were statistically significant, with the lowest scores in the Central area, the Canary Islands, and Ceuta and Melilla (chi-square test, $\mathrm{P}=0.002$ ).

The relationship between the knowledge source and the number of known devices was assessed using two contingency tables (data not shown). An ANOVA test identified statistically significant differences $(\mathrm{P}<0.05)$ between scores of pharmacists with no knowledge source and those with one source. Differences were not statistically significant for those with more than one knowledge source. In contrast, the number of known devices did not account for statistically significant differences (data not shown).

\section{DISCUSSION}

Community pharmacists are increasingly involved in the healthcare of patients with chronic diseases [21,22], including patients with chronic respiratory conditions [23]. It has been shown that pharmaceutical care of patients with obstructive respiratory diseases improves medication adherence [24-27] and achieves a better use of inhalers [26, 28-30] and control of the disease [31, 32]. In a randomized controlled study to investigate the effect of a simple educational intervention concerning DPI technique delivered by community pharmacists to patients with asthma, a simple educational intervention taking only $2.5 \mathrm{~min}$ and targeting inhaler technique was feasible for delivery by community pharmacists and resulted in improved clinical and humanistic outcomes for patients with asthma [33]. Also, in a comparison of the effectiveness of four different instructional interventions in training proper inhaler technique, a 2-minute pharmacist counseling session was more effective than to read a metered dose inhaler (MDI) package insert pamphlet or to watch a Centers for Disease Control and Prevention video or YouTube video demonstrating MDI technique [34].

The present survey among Spanish community pharmacists showed interesting findings. Firstly, knowledge regarding inhaled therapy was inadequate or limited in $76.4 \%$ of the study sample, and only $6 \%$ of community pharmacists had an adequate knowledge. Secondly, patient education was unsatisfactory. The skills of patients when dispensing an inhaler was checked only sometimes or almost never in $65.6 \%$ of the cases. Also, training in correct inhaler technique was not provided by $33.1 \%$ of respondents and the inhalation technique was not checked by $73.3 \%$. 
Other studies, although with a different methodology, also found the poor knowledge of inhaled therapy among community pharmacists. In a sample of Spanish community pharmacists who were asked to demonstrate the inhalation technique with three inhalers, the mean percentage of correct steps was $47.4 \%$ with a pMDI, 55.9\% with Turbuhaler ${ }^{\mathrm{TM}}$ and $49.4 \%$ with Accuhaler ${ }^{\mathrm{TM}}$ [35]. In a study carried out in Jordan in a convenience sample of 31 pharmacists who attended an educational workshop, at the initial assessment few pharmacists demonstrated correct technique (Turbuhaler ${ }^{\mathrm{TM}}$ 13\%, Diskus ${ }^{\mathrm{TM}} 6 \%$ ) but 2 y after training, pharmacists in the intervention group showed significantly better inhaler technique than pharmacists in the control group $(\mathrm{P}<0.05)$ for Turbuhaler ${ }^{\mathrm{TM}}$ and Diskus ${ }^{\mathrm{TM}}(83 \%$ vs. $11 \% ; 75 \%$ vs. $11 \%$, respectively) [36]. In a study that evaluated the most problematic steps in the use of Diskus ${ }^{\mathrm{TM}}$ and Turbuhaler ${ }^{\mathrm{TM}}$ among pharmacists from to countries, Jordan and Australia, few professionals in either country demonstrated correct technique for step 3 (exhale to residual volume) or step 4 (exhale away from the device) [37]. In a French study, among the 57 pharmacists who gave a demonstration of the use of inhaler devices, $16.3 \%$ showed all the steps in the use of a metered dose aerosol [38].

However, different studies have shown that educational interventions improve community pharmacists' competence in inhaled therapy. In a study in which community pharmacists were asked to demonstrate the proper steps in the actuation sequences of Diskus $^{\mathrm{TM}}$ and Turbuhaler ${ }^{\mathrm{TM}}$ and then received an instructional session on the proper inhalation technique, the mean change between baseline and post-instruction percentage scores for Diskus $^{\mathrm{TM}}$ and Turbuhaler ${ }^{\mathrm{TM}}$ were $22.6 \pm 18.7 \%$ and $17.1 \pm 15.4 \%$, respectively [39]. Therefore, a single instructional session can dramatically improve a community pharmacist's ability to demonstrate the correct method of actuation [39]. As previously mentioned, the sample of 31 pharmacists in the study carried out in Jordan, also showed significant increases in the correct use of the inhaler technique 2 y after training as compared to pharmacists assigned to the non-intervention group [36]. Similarly, skills in the use of pMDI, breath-actuated pMDI and DPI improved significantly $(\mathrm{P}<0.001)$ after $10 \mathrm{y}$ of continuing pharmaceutical education [38, 40]. Some efforts have been made to improve Spanish community pharmacists' knowledge inhaled therapy knowledge, but our survey shows that more educational initiatives are needed.

More than half of the respondents correctly identified the most important step for using a pMDI or DPI inhaler (items 6 and 7 of the questionnaire). However, $81.5 \%$ of those surveyed failed to respond correctly to question 8, which asked about the most important variable when prescribing an inhaler device (the correct answer "Patients' preferences" was selected by only $18.5 \%$ of pharmacists). There were no differences in knowledge of inhaled therapy according to sex, age and size of the population of the area. However, scores by geographical area differed. This result may indicate that pharmacist education requires different approaches according to a geographical area.

The number of devices known did not modify the scores relating to knowledge of inhaled therapy. By contrast, the number of knowledge sources did: pharmacists with one knowledge source had higher scores than their colleagues with none $(p<0.05)$ or more than one source ( $\mathrm{p}$ non-significant). Package insert and personal experience were the most frequent knowledge sources, but that does not necessarily mean that all respondents with one source used either one or the other. It may perhaps be useful to analyze scores by knowledge source. Nonetheless, this result highlighted the importance of being informed about inhalation devices. In agreement with our findings, in a Canadian study [41], the only knowledge source for $33 \%$ of community pharmacists was the package insert, while $40 \%$ had received instruction from a pharmaceutical representative. The authors concluded that community pharmacists' knowledge of inhalation devices was proportional to the length of time the device had been available.

Patient education has been assessed in studies with simulated patients. In a study carried out in the United States that evaluated a pharmacist's practice in patient education when dispensing an MDI to an investigator posing as a patient, only $13 \%$ of pharmacists offered initially to provide information regarding correct technique, and when asked for instruction on MDI usage, 53\% of pharmacists offered information [42]. Also, in a simulated patient study performed in 160 Australian community pharmacies in 2009, only $24 \%$ of pharmacists provided counseling on inhalation technique [43]. Furthermore, in a recent survey in a sample of 77 Australian community pharmacists, $54 \%$ reported that they demonstrated the inhalation technique for new inhaled medicines and $35 \%$ checked for written asthma self-management plan possession. Although $65 \%$ of pharmacists reported confidence in communication skills, most pharmacists were not confident in setting short-/long-term goals with the patient and career for managing asthma at home [44]. This study concludes that Pharmacists need more appropriate continuing education programs that can translate into improved pediatric asthma self-management practices and thus improved asthma outcomes in children. In fact, these and many other studies have addressed the effects of education and assessment by community pharmacists of patients with asthma or COPD by community pharmacists [15, 26, 30-33,45-47], including children with asthma [58] and elderly subjects [59]. Moreover, in community pharmacies from different countries several initiatives to improve inhaler use have been implemented, such as the Australian Inhaler Technique Labels [50], the Pharmacy Asthma Management Service (PAMS) [53], and the Danish Inhaler Technique Assessment Service (ITAS) [60].

\section{CONCLUSION}

Despite Spanish community pharmacists' increasing involvement of in-patient care, their knowledge of, and attitudes towards, inhaled therapy needs to improve in order to provide better patient education.

\section{ACKNOWLEDGEMENT}

The authors thank Marta Pulido, MD, for editing the manuscript and editorial assistance.

\section{CONFLICTS OF INTERESTS}

J. Giner received honoraria for participating in meetings, congresses, and research projects organized by Chiesi España, AstraZeneca, Boehringer-Ingelheim, Laboratorios Dr. Esteve, GlaxoSmithKline, MSD, Novartis, Sandoz, Pfizer, Teva, and Takeda.

P. Roura has participated in meetings and research projects organized by Chiesi España and Pfizer.

F. Burgos has received fees for participating in meetings, congresses, and research projects organized by the European Respiratory Society, Teva and Linkcare Health Services.

E. Tarragona received a stipend as a Medical Advisor from Chiesi España.

V. Plaza has received fees for speaking at sponsored meetings from AstraZeneca, Chiesi, GlaxoSmithKline, Merck, Novartis, and Pfizer, and as a consultant for Orion and Teva. He also received support for attending meetings organized by Boehringer Ingelheim and for research projects funded by government agencies, not-for-profit organizations, and Chiesi España, Menarini, and Merck.

B. Torres and D. Castillo: No conflicts of interest to be declared.

\section{REFERENCES}

1. Plaza V, Calle M, Molina J, Quirce C, Sanchís J, Viejo JL, et al. External validation of the recommendations of the multidisciplinary consensus about inhaled therapies. Arch Bronconeumol 2012;48:189-96.

2. Mortensen NP, Hickey AJ. Targeting inhaled therapy beyond the lungs. Respiration 2014;88:353-4.

3. Global Initiative for Asthma (GINA). Global Strategy for Asthma Management and Prevention, 2015. Available at: http://www. ginasthma. org. Date accessed: September 15, 2015.

4. GEMA 4.0. Spanish Guideline on the Management of Asthma; 2015. Availablle from: http://www.gemasma.com/. [Last accessed on 15 Sep 2015]. 
5. Miravitlles M, Soler-Cataluña JJ, Calle M, Molina J, Almagro P, Quintano JA, et al. Spanish guideline for COPD (GesEPOC). Arch Bronconeumol 2014;50 Suppl 1:1-16.

6. Global Initiative for Chronic Obstructive Lung Disease (GOLD). Global Strategy for the Diagnosis, Management, and Prevention of Chronic Obstructive Pulmonary Disease. Updated; 2015. Available from: http://www.goldcopd.org/uploads/users/ files/GOLD_Report_2015_Apr2.pdf. [Last accessed on 15 Sep 2015].

7. Broeders ME, Sanchis J, Levy ML, Crompton GK, Dekhuijzen PR. ADMIT series--issues in inhalation therapy. 2. Improving technique and clinical effectiveness. Primary Care Respiratory J 2009;18:76-82.

8. Sanchis J, Corrigan C, Levy ML, Viejo JL. Inhaler devices-from theory to practice. Respir Med 2013;107:495-502.

9. Voshaar T, Spinola M, Linnane P, Campanini A, Lock D, Lafratta $A$, et al. Comparing usability of NEXThaler(®) with other inhaled corticosteroid/long-acting $\beta 2$-agonist fixed combination dry powder inhalers in asthma patients. J Aerosol Med Pulm Drug Delivery 2014;27:363-70.

10. SEPAR-ALAT consensus for inhaled therapies. Arch Bronconeumol 2013;49 Suppl 1:2-14.

11. Laube BL, Janssens HM, de Jongh FHC, Devadason SG, Dhand R, Diot $\mathrm{P}$, et al. What the pulmonary specialist should know about the new inhalation therapies. Eur Respir J 2011;37:1308-31.

12. Role of the pharmacist in improving asthma care. National Asthma Education and Prevention Program. Am J Health Syst Pharm 1995;52:1411-6.

13. Castillo D, Burgos F, Guayta R, Giner J, Lozano P, Estrada M, et al. Airflow obstruction case finding in community pharmacies: a novel strategy to reduce COPD underdiagnosis. Respir Med 2015;109:475-82.

14. Le Gouldec N, Ait Tahar H, Sonneville A. The physicianpharmacist team in the education of patients concerning inhalant therapy. Allerg Immunol 2001;33:383-7.

15. Stuurman-Bieze AGG, de Boer WO, Kokenberg MEAP, Hugtenburg JG, de Jong-van den Berg LTW, Tromp TFJ. Complex pharmaceutical care intervention in pulmonary care: part A. The process and pharmacists' professional satisfaction. Pharm World Sci 2005;27:376-84.

16. Balter M, Ernst P, Watson W. Asthma worsenings: approaches to prevention and management from the Asthma Worsenings Working Group. Can Respir J 2008;15 Suppl B:1B-19B.

17. Bryant J, McDonald VM, Boyes A, Sanson-Fisher R, Paul C, Melville J. Improving medication adherence in chronic obstructive pulmonary disease: a systematic review. Respir Res 2013;14:109.

18. Bosnic-Anticevich SZ, Stuart M, Mackson J, Cvetkovski B, Sainsbury E, Armour C, et al. Development and evaluation of an innovative model of inter-professional education focused on asthma medication use. BMC Med Educ 2014;14:72.

19. Plaza V, Sanchis J, Roura P, Molina J, Calle M, Quirce S, et al. Physicians' knowledge of inhaler devices and inhalation techniques remains poor in Spain. J Aerosol Med Pulm Drug Delivery 2012;25:16-22.

20. Giner J, Roura P, Hernández C, Torrejón M, Peiró M, Fernández MJ, et al. Knowledge and attitudes of nurses in spain about inhaled therapy: Results of a national survey. J Aerosol Med Pulm Drug Delivery 2015. Doi:10.1089/jamp.2014.1198.

21. Gorgas Torner MQ, Pàez Vives F, Camós Ramió J, de Puig Cabrera E, Jolonch Santasusagna P, Horns Peipoch E, et al. Integrated pharmaceutical care programme in patients with chronic diseases. Farm Hosp 2012;36:229-39.

22. Van Boven JFM, Stuurman Bieze AGG, Hiddink EG, Postma MJ Vegter S. Medication monitoring and optimization: a targeted pharmacist program for effective and cost-effective improvement of chronic therapy adherence. J Manag Care Spec Pharm 2014;20:786-92.

23. Fathima M, Naik-Panvelkar P, Saini B, Armour CL. The role of community pharmacists in screening and subsequent management of chronic respiratory diseases: a systematic review. Pharm Pract 2013;11:228-45.

24. Van Boven JFM, Hiddink EG, Stuurman-Bieze AGG, SchuilingVeninga CCM, Postma MJ, Vegter S. The pharmacists' potential to provide targets for interventions to optimize pharmacotherapy in patients with asthma. Int J Clin Pharm 2013;35:1075-82.

25. Zhong H, Ni XJ, Cui M, Liu XY. Evaluation of pharmacist care for patients with chronic obstructive pulmonary disease: a systematic review and meta-analysis. Int J Clin Pharm 2014;36:1230-40.

26. Tommelein E, Mehuys E, Van Hees T, Adriaens E, Van Bortel L, Christiaens $\mathrm{T}$, et al. Effectiveness of pharmaceutical care for patients with chronic obstructive pulmonary disease (PHARMACOP): a randomized controlled trial. $\mathrm{Br} \mathrm{J}$ Clin Pharmacol 2014;77:756-66.

27. Wright D, Twigg M, Barton G, Thornley T, Kerr C. An evaluation of a multi-site community pharmacy-based chronic obstructive pulmonary disease support service. Int J Pharm Pract 2015;23:36-43.

28. Hämmerlein A, Müller U, Schulz M. Pharmacist-led intervention study to improve inhalation technique in asthma and COPD patients. J Evaluation Clin Practice 2011;17:61-70.

29. Takemura M, Mitsui K, Ido M, Matsumoto M, Koyama M, Inoue $\mathrm{D}$, et al. Impact of a network system for providing proper inhalation technique by community pharmacists. J Asthma 2012;49:535-41.

30. Toumas Shehata M, Price D, Basheti IA, Bosnic-Anticevich S. Exploring the role of quantitative feedback in inhaler technique education: a cluster-randomised, two-arm, parallel group, repeated-measures study. NPJ Prim Care Respir Med 2014;24:14071.

31. Armour CL, LeMay K, Saini B, Reddel HK, Bosnic-Anticevich SZ, Smith LD, et al. Using the community pharmacy to identify patients at risk of poor asthma control and factors which contribute to this poor control. J Asthma 2011;48:914-22.

32. Armour CL, Reddel HK, LeMay KS, Saini B, Smith LD, BosnicAnticevich SZ, et al. Feasibility and effectiveness of an evidencebased asthma service in Australian community pharmacies: a pragmatic cluster randomized trial. J Asthma 2013;50:302-9.

33. Basheti IA, Reddel HK, Armour CL, Bosnic-Anticevich SZ. Improved asthma outcomes with a simple inhaler technique intervention by community pharmacists. J Allergy Clin Immunol 2007;119:1537-8.

34. Axtell S, Haines S, Fairclough J. Effectiveness of various methods of teaching proper inhaler technique: the importance of pharmacist counseling. J Pharm Pract 2016. Doi:10.1177/0897190016628961.

35. Andrés J, Iñesta A, Huetos J, Rodrigo N. Knowledge of inhalation technique of antiasthma drugs by community pharmacists. Pharm Care Esp 2004;6:191-4.

36. Basheti IA, Armour CL, Reddel HK, Bosnic-Anticevich SZ. Longterm maintenance of pharmacists' inhaler technique demonstration skills. Am J Pharm Educ 2009;73:32.

37. Basheti IA, Qunaibi E, Bosnic-Anticevich SZ, Armour CL, Khater $\mathrm{S}$, Omas $\mathrm{M}$, et al. User error with diskus and turbuhaler by asthma patients and pharmacists in Jordan and Australia. Respir Care 2011;56:1916-23.

38. Casset A, Rebotier P, Lieutier-Colas F, Glasser N, Heitz C, Saigne $\mathrm{J}$, et al. Pharmacists' role in the management of asthma: a survey of 120 pharmacists in Bas-Rhin. Rev Mal Respir 2004;21:925-33.

39. Cain WT, Cable G, Oppenheimer JJ. The ability of the community pharmacist to learn the proper actuation techniques of inhaler devices. J Allergy Clin Immunol 2001;108:918-20.

40. Casset A, Meunier-Spitz M, Rebotier P, Lefèvre H, Barth C, Heitz $\mathrm{C}$, et al. Asthma management and inhalation techniques among community pharmacists in 2009: A comparison with the 1999 survey. J Asthma 2014;51:964-73.

41. Kesten S, Zive K, Chapman KR. Pharmacist knowledge and ability to use inhaled medication delivery systems. Chest 1993;104:1737-42.

42. Mickle TR, Self TH, Farr GE, Bess DT, Tsiu SJ, Caldwell FL. Evaluation of pharmacists' practice in patient education when dispensing a metered-dose inhaler. Dalian Institute of Chem Physics 1990;24:927-30.

43. Schneider CR, Everett AW, Geelhoed E, Kendall PA, Clifford RM. Measuring the assessment and counseling provided with the 
supply of nonprescription asthma reliever medication: a simulated patient study. Ann Pharmacother 2009;43:1512-8.

44. Elaro A, Shah S, Armour CL, Bosnic-Anticevich S. A snapshot of pharmacist attitudes and behaviors surrounding the management of pediatric asthma. J Asthma 2015;52:957-68.

45. Cordina M, McElnay JC, Hughes CM. Assessment of a community pharmacy-based program for patients with asthma. Pharmacotherapy 2001;21:1196-203.

46. Diamond SA, Chapman KR. The impact of a nationally coordinated pharmacy-based asthma education intervention. Can Respir J 2001;8:261-5.

47. Laufenberg-Horstmann E, DeVore E, Bassuener K. The coulee region community pharmacy asthma intervention study. J Am Pharm Assoc 2003;46:738-46.

48. Basheti IA, Reddel HK, Armour CL, Bosnic-Anticevich SZ. Counseling about Turbuhaler technique: needs assessment and effective strategies for community pharmacists. Respir Care 2005;50:617-23.

49. Kritikos V, Armour CL, Bosnic-Anticevich SZ. Interactive smallgroup asthma education in the community pharmacy setting: a pilot study. J Asthma 2007;44:57-64.

50. Basheti IA, Armour CL, Bosnic-Anticevich SZ, Reddel HK. Evaluation of a novel educational strategy, including inhalerbased reminder labels, to improve asthma inhaler technique. Patient Educ Couns 2008;72:26-33.

51. De Vries TW, van den Berg PB, Duiverman EJ, de Jong-van, den Berg LTW. Effect of a minimal pharmacy intervention on improvement of adherence to asthma guidelines. Arch Dis Child 2010;95:302-4.

52. Naik Panvelkar P, Armour C, Saini B. Community pharmacybased asthma services--what do patients prefer? J Asthma 2010;47:1085-93.

53. Saini B, Krass I, Smith L, Bosnic-Anticevich S, Armour C. Role of community pharmacists in asthma-Australian research highlighting pathways for future primary care models. Australas Med J 2011;4:190-200.

54. Giraud V, Allaert FA, Roche N. Inhaler technique and asthma: feasability and acceptability of training by pharmacists. Respir Med 2011;105:1815-22.

55. García-Cárdenas V, Sabater-Hernández D, Kenny P, MartínezMartínez F, Faus MJ, Benrimoj SI. Effect of a pharmacist intervention on asthma control. A cluster randomised trial. Respir Med 2013;107:1346-55.

56. Bereznicki BJ, Peterson G, Jackson S, Walters EH, George J, Stewart $\mathrm{K}$, et al. Uptake and effectiveness of a community pharmacy intervention programme to improve asthma management. J Clin Pharm Ther 2013;38:212-8.

57. Ottenbros S, Teichert M, de Groot R, Griens F, Sodihardjo F, Wensing $\mathrm{M}$, et al. Pharmacist-led intervention study to improve drug therapy in asthma and COPD patients. Int J Clin Pharm 2014;36:336-44.

58. Elaro A, Shah S, Pomare LN, L Armour C, Z Bosnic-Anticevich S. PACE: Pharmacists use the power of communication in paediatric asthma. Int J Clin Pharm 2014;36:976-85.

59. Nobles J, Hutchison AM. Potential problems and solutions with inhaler use in elderly COPD patients. Consultpharm 2014;29:753-6.

60. Kaae S, Christensen ST. Exploring long-term implementation of cognitive services in the community pharmacies a qualitative study. Pharm Pract (Granada) 2012;10:151-8.

\section{How to cite this article}

- Jordi Giner, Pere Roura, Berta Torres, Felip Burgos, Diego Castillo, Eduard Tarragona, Vicente Plaza. Knowledge, attitudes, and preferences among spanish community pharmacists regarding inhaled therapy (The optim pharmacy study). Int J Pharm Pharm Sci 2016;8(9):53-60. 